OPEN ACCESS

Edited by:

Sinuhe Hahn,

University of Basel, Switzerland

Reviewed by:

Stavros Giaglis,

University of Basel, Switzerland

Anna Maria Piccinini,

University of Nottingham, UK

Stefan Gebhardt,

Stellenbosch University,

South Africa

*Correspondence:

Angela P. Cadavid

angela.cadavid@udea.edu.co

Specialty section:

This article was submitted

to Inflammation,

a section of the journal

Frontiers in Immunology

Received: 15 October 2016

Accepted: 23 February 2017

Published: 15 March 2017

Citation:

Cadavid AP (2017) Aspirin: The Mechanism of Action Revisited in the Context of Pregnancy Complications.

Front. Immunol. 8:261.

doi: 10.3389/fimmu.2017.00261

\section{Aspirin: The Mechanism of Action Revisited in the Context of Pregnancy Complications}

\author{
Angela P. Cadavid*
}

Reproduction Group, Department of Microbiology and Parasitology, School of Medicine, University of Antioquia, Medellin, Colombia

Aspirin is one of the most frequently used and cheapest drugs in medicine. It belongs to the non-steroidal anti-inflammatory drugs with a wide range of pharmacological activities, including analgesic, antipyretic, and antiplatelet properties. Currently, it is accepted to prescribe a low dose of aspirin to pregnant women who are at high risk of preeclampsia (PE) because it reduces the onset of this complication. Another pregnancy alteration in which a low dose of aspirin is recommended is the obstetric antiphospholipid syndrome (APS). The most recognized mechanism of action of aspirin is to inhibit the synthesis of prostaglandins but this by itself does not explain the repertoire of anti-inflammatory effects of aspirin. Later, another mechanism was described: the induction of the production of aspirin-triggered lipoxins (ATLS) from arachidonic acid by acetylation of the enzyme cyclooxygenase-2. The availability of a stable analog of ATL has stimulated investigations on the use of this analog and it has been found that, similar to endogenously produced lipoxins, ATL resolves inflammation and acts as antioxidant and immunomodulator. If we consider that in PE and in the obstetric APS, there is an underlying inflammatory process, aspirin might be used based on the induction of ATL. The objective of this review is to revisit the old and new mechanisms of action of aspirin. In particular, it intends to show other potential uses of this drug to prevent certain pregnancy complications in the light of its ability to induce anti-inflammatory and pro-resolving lipid-derived mediators.

Keywords: anti-inflammatory, aspirin-triggered lipoxins, pro-resolving lipid-derived mediators, obstetric antiphospholipid syndrome, preeclampsia, pregnancy complications

\section{INTRODUCTION}

Aspirin is the trade name for acetylsalicylic acid coined by the Bayer laboratories. In many countries, it remains a registered trademark of this company, whereas in others aspirin has become the generic name of this substance.

Aspirin in low doses is the single most cost-effective medicine for the prevention of secondary events of thrombosis. Furthermore, low doses of aspirin (LDA) are widely used in the prevention of diverse alterations of gestation such as preeclampsia (PE) and the obstetric antiphospholipid syndrome (APS). Although controversy persists concerning the real efficiency and empirical use of this compound, its prescription is very common in high-risk pregnancies; moreover, its cost is low and it is relatively safe and easily accessible to all (1-7). 
As a part of the inflammatory response to an injury, the immune system develops mechanisms of control to this response, through the production of pro-resolving lipid mediators including lipoxins, resolvins, protectins, and maresins. These mediators are produced from arachidonic acid (AA) or from omega-3 polyunsaturated fatty acids (PUFAs), through different molecular mechanisms but that imply transcellular biosynthesis with the participation of different enzymes (8). Interestingly, aspirin induces the production of some pro-resolving lipid-derived mediators very similar to the ones produced endogenously that bind to the same receptor, conferring to aspirin some special properties in the resolution of inflammation (9), in addition to its already known pharmacological effects as analgesic, antipyretic, and antiplatelet drug.

This review aims to revisit the old and new mechanisms of aspirin's actions and particularly show other possible effects in some complications of pregnancy in which aspirin has been used in an empirical and controversial way.

\section{A QUICK GLANCE ASPIRIN-TRIGGERED (AT) THE HISTORY OF ASPIRIN DISCOVERY}

Aspirin is one of the oldest drugs in use, and it is a very representative example of how natural products can be optimized with mild chemical manipulations; its use dates back to 1,500 years B.C., when the Egyptians used crude infusions of myrtle bark for rheumatism and back pain. A thousand years later, Hippocrates prescribed bark and leaves of the willow to relieve fever and pain. In 1763, the Reverend Stone reported a successful treatment of 50 patients in febrile states with willow extract. In 1828, Buchner purified salicin and proposed it as the main component with antipyretic activity of this extract. In 1838, Piria successfully synthesized salicylic acid from salicin. In 1897, Hoffman achieved acetylsalicylic acid as a chemically pure and stable compound; in 1899, its therapeutic properties as an analgesic and anti-inflammatory compound were described and, in 1900, it was introduced into the market in the form of aspirin tablets $(10,11)$.

For many years, aspirin was widely used as household medicine for the treatment of fever, pain, and inflammation even though its mechanism of action was unknown. It was not until 1971 that the Vane showed that aspirin suppressed the production of some eicosanoids derived from AA such as prostaglandins (12). Later studies demonstrated that the acetylation of platelet cyclooxygenase (COX) by aspirin inhibits thromboxane formation and explains its antithrombotic effects (13).

As of 1979, reports of different actions of aspirin have been flourishing and include its use in the prevention of colon cancer (14), cardiovascular diseases such as myocardial infarction, strokes, and atherothrombotic events $(15,16)$, as well as the report that regular intake of aspirin during pregnancy reduces the risk of PE (17). One of the discoveries that interests us in the context of this review is the detection in 1989 by Claria and Serhan, of the generation of aspirin-triggered lipoxins (ATLs) from AA, by the interaction of acetylated COX-2 with the 5-lipoxygenase of white cells (18).

\section{MECHANISMS OF ACTION OF ASPIRIN}

Aspirin is a prototype of non-steroidal anti-inflammatory drugs (NSAIDs), and member of the family of salicylates that have in common salicylic acid as the active agent. Salicylic acid is composed of a benzene ring and two radicals, one hydroxyl and one carboxyl. In the acetylsalicylic acid or aspirin, the hydroxyl group salicylate is transformed into an acetyl group by esterification. The pharmacological properties of aspirin are similar to those of salicylates, but also to the biological actions attributed to salicylate itself, and it has other independent effects due to its reactive acetate group (11). Both components, salicylate and acetate groups, are biologically active and act independently of each other at different sites. A summary of the pharmacological actions of these components of aspirin are summarized in Figure 1 (18-29).

LDA (e.g., 75-100 mg/day) are sufficient to irreversibly acetylate serine 530 of COX-1, inhibiting platelet generation of thromboxane-A2, resulting in an antithrombotic effect. Intermediate doses of aspirin (650 mg to $4 \mathrm{~g} /$ day) inhibit COX-1 and COX-2 (30). Additionally, aspirin can induce the production of ATL (18). This lipid mediator exerts its actions by binding to a G-protein-coupled receptor, named ALXR (9). A simple scheme of the metabolic pathways of AA is shown in Figure 2.

\section{USE OF ASPIRIN IN PREVENTION OF PE}

Preeclampsia is a multisystem disorder defined by persistent hypertension during pregnancy or postpartum period that may be associated with proteinuria, thrombocytopenia, impaired liver function, progressive renal insufficiency, pulmonary edema, or cerebral disturbances (31). It is generally accepted that PE originates from the placenta, since poor trophoblast invasion and remodeling of spiral arteries occur, leading to reduced utero-placental arterial flow and episodes of hypoxia/reperfusion (32). These abnormalities in the perfusion of placenta generate reactive oxygen species that, after a while, result in the release of cytokines, lipid peroxides, and syncytiotrophoblast microfragments from the placenta into the maternal circulation (33). Hence, in PE, the increased inflammation, oxidative stress, and endothelial dysfunction are key pathogenic features (34).

Since 1979, when the utility of aspirin intake in pregnancy was reported to prevent $\mathrm{PE}$ (17), many reports with controversial results on the efficiency of this drug were reported: two multicenter studies found a slight benefit of aspirin in preventing PE $(35,36)$. Other randomized placebo-controlled trials suggest that LDA did not reduce the rate of PE [relative risk (RR), 0.7, 95\% confidence interval (CI), 0.3-1.7] (37). On the other hand of the controversy, other reports in the literature showed results in favor of the beneficial effects of LDA to prevent PE: in a systematic review of the literature of 46 trials involving 32,891 patients, a moderate benefit of aspirin was found in preventing PE; LDA reduced the risk of $\mathrm{PE}$ by $17 \%$ (RR, 0.83, 95\% CI, 0.77-0.89). These results were statistically significant independent of whether patients had moderate or high risk of PE, or whether they were included in a placebo-controlled trial (1). In a recent metaanalysis, it was shown that LDA used before the 16th week of pregnancy reduces the risk of PE (RR, 0.57; 95\% CI, 0.43-0.75; 


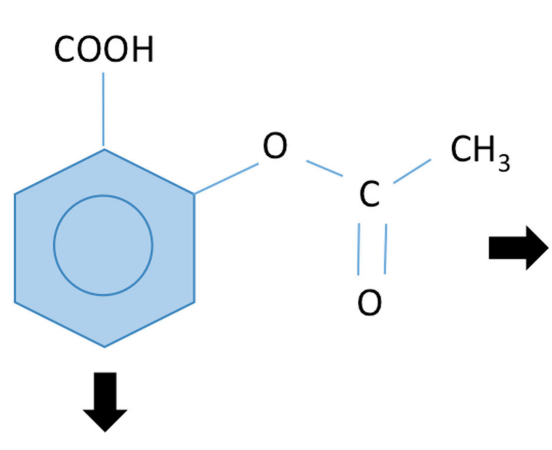
Salicylate group
$\diamond$ Inhibition of binding of CCAAT/enhancer- binding protein- $\beta$ to its promoter region of COX-2 and of inducible nitric oxide synthase (iNOS) genes (19).
$\diamond$ Induction of proton transportation across cell membranes which leads to uncoupling of oxidative phosphorylation which in turn showed a decreased proliferation and cell death in tumoral cells $(20,21)$.
$\diamond$ Prevent activation of genes involved in the pathogenesis of the inflammatory response through blocking activation by NF-kB $(22,23)$.

\section{$\underline{\text { Reactive acetyl group }}$}

$\diamond$ Irreversible inactivation of platelet COX-1 by acetylation of serine-529 leading to inhibition of thromboxane-A2 production avoiding the vasoconstriction and platelet aggregation induced by this prostanoid (24).

$\diamond$ Acetylation of COX-2 (serine-516) inhibiting prostaglandin production but redirecting its catalytic activity, leading to the production of 15(R)-hydroxyleicosatetraenoic acid as a substrate for new biologically active mediators aspirintriggered lipoxins (ATL) (18).

$\diamond$ Acetylation of endothelial NO synthase (eNOS) eliciting nitric oxide release from vascular endothelium (25).

$\diamond$ Induction of expression and enzymatic activity of the heme oxygenase-1 (HO-1) in endothelial cells, that catabolizes heme, and contributes to the reduction of oxidative stress, injury, and inflammation $(26,27)$.

$\diamond$ Acetylation of multiple cellular proteins such as the tumor suppressor protein $\mathrm{p} 53$, fibrinogen and human serum albumin, among others $(28,29)$.

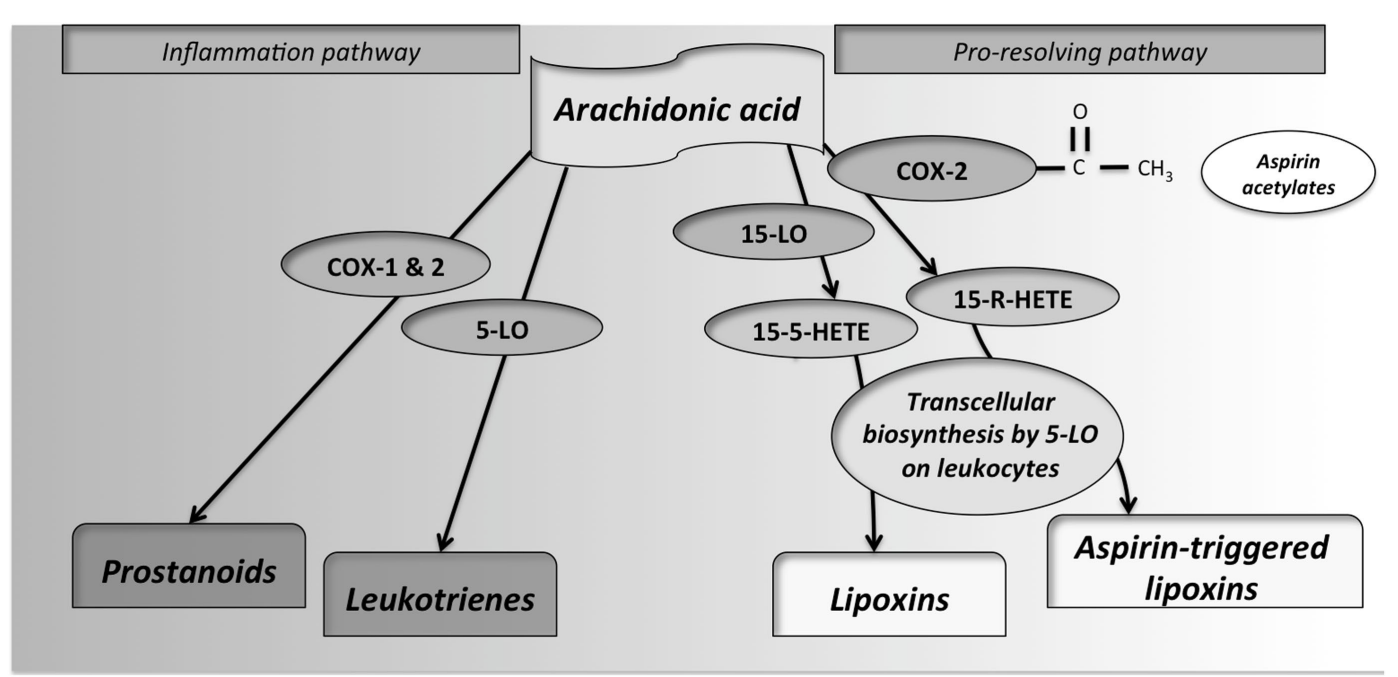

FIGURE 2 | Synthesis of pro-inflammatory and pro-resolving lipid mediators from arachidonic acid (AA). By the action of cyclooxygenases-1 and -2, the prostanoids prostacyclins, prostaglandins and thromboxanes, are produced. These enzymes are inhibited by non-steroidal anti-inflammatory drugs, including aspirin. If AA interacts with 5-lypoxigenase (5-LO), leukotrienes, also important mediators of inflammation, are produced. In the control of inflammatory response, the metabolite 15(S)-hydroxy-eicosatetraenoic acid (15S-HETE) is produced from LO from different cellular sources. This metabolite, through interaction with 5-LO in leukocytes by transcellular biosynthesis, produces some lipid mediators so-called lipoxins. Additionally, as an exclusive property of aspirin, by its reactive acetate group, aspirin can acetylate the active site of cyclooxygenase (COX)-2. This interaction inhibits its catalytic activity as a COX but redirects it, leading to the production of 15R-HETE from AA. 15R-HETE is then also converted through transcellular biosynthesis, by white-cell 5-LO, into aspirin-triggered lipoxins. 
$p<0.001$ ) (3). However, other authors did not find differences in the beneficial effect of aspirin whether treatment was started before or after 16 weeks of gestation (38).

Regarding the risks of using LDA during pregnancy, most studies have found no association between its use and complications in the mother or fetus, whether used in the first or third trimester. These studies show the lack of association of the use of such treatment with congenital anomalies, neonatal intraventricular hemorrhage, premature closure of the ductus arteriosus, maternal postpartum bleeding, or placental abruption $(1,39,40)$. An adverse event such as vaginal bleeding not associated with gestational loss was described (41). Other maternal factors such as allergy or resistance to aspirin, in addition to gastric intolerance, could counterindicate the use of LDA in pregnancy (42).

Despite these controversial results, the preventive use of LDA in women at high risk for PE such as medical history of previous severe-PE, diabetes, chronic hypertension, renal disease, or autoimmune disease seems to be accepted $(1,39,40)$. However, the controversy regarding the use of LDA persists in low-risk women. Currently, a panel of diagnostic tests exists to determine PE risk that includes uterine artery Doppler pulsatility index, and some placental biomarkers such as pregnancy-associated plasma protein A and placental growth factors (PLGF) (42). However, in developing countries, it is costly to have access to such tests and in that sense, it would be beneficial to recommend the use of LDA in women in whom PE risk is suspected.

\section{USE OF ASPIRIN IN OBSTETRIC APS}

Antiphospholipid syndrome is an autoimmune disorder characterized by the persistent presence of antiphospholipid (aPL) antibodies and clinical manifestations of vascular thrombosis or obstetrical complications, and also both aspects of the syndrome. Clinical criteria for obstetric APS include at least one of the following pathologies: early or late gestational loss, intrauterine growth restriction, placental insufficiency, or PE (43).

The mechanisms of injury of aPL involve activation of the endothelium, platelets, and monocytes, and complement activation and inhibition of anticoagulant proteins, leading to the phenomena of inflammation and thrombosis. It has been demonstrated that aPL-associated obstetric complications are induced mainly by an inflammatory process and placental insufficiency rather than by thrombotic events at the maternal-fetal interface (44-49). aPL interferes with the migration, proliferation, and differentiation of trophoblast cells and decreases the production of placental human chorionic gonadotropin (hCG) (47, 50-58). Furthermore, aPL impairs interaction between the invading trophoblast and the endothelium of the uterine spiral arteries, which is a key process where spiral arteries are transformed into high-capacity low-resistance vessels to supply the growing nutritional demands of the fetus and the placenta (59).

Low doses of aspirin, alone or combined with low molecular heparin, is one of the preferred treatments in pregnant women with obstetric APS $(4,5,60)$. Although a meta-analysis published in 2005 concluded that the combination of LDA plus unfractioned heparin had up to a $54 \%$ chance of reducing fetal loss (61), a subsequent randomized controlled-clinical trial did not find significant differences between the observed outcome for APS patients treated with aspirin alone in comparison with combined therapy of aspirin plus low molecular weight heparin (79.1 and $77.8 \%$ of live births, respectively) (60). Because these protocols fail in about $20 \%$ of pregnant APS women, additional therapies have been proposed to add to conventional therapies $(62,63)$.

Low doses of aspirin reduced embryo resorption in a model of experimental APS induced in pregnant mice (64) and restored placental hCG secretion abolished by the effect of aPL (47). Over a period of 25 years, in our Reproduction Group of the University of Antioquia, LDA has been used alone or combined with other therapies to prevent recurrent spontaneous abortion. The other therapies include progesterone, heparin, folic acid, or lymphocyte immunotherapy. In a group of 111 women with a history of three or more abortions, who were treated with aspirin during their pregnancy, a coadjuvant effect of the treatment including aspirin was observed: if the patients who received some treatment were compared with patients non-treated at all, the odds ratio (OR) was $0.33(0.13-0.81, p=0.01)$; if the treatment including aspirin was compared with no treatment, the OR was $0.13(0.04-0.43$, $p<0.001$ ) (65). Additionally, a prospective study of "single therapy" with aspirin/heparin in patients with recurrent spontaneous abortion was carried out. These patients displayed autoimmune and alloimmune alterations, but lymphocyte immunotherapy was not administered to them; the gestational success in this group of patients was of $90.9 \%(10 / 11)$ versus $75.0 \%(6 / 8)$ in the concurrent group receiving both therapies (66). These results are empirical and lack the rigor of controlled-clinical trials, but encouraged us to continue exploring the use of LDA as a simple therapy in patients with recurrent pregnancy loss, associated or not with obstetric APS.

\section{CLINICAL AND EXPERIMENTAL EFFECTS OF ATL}

Aspirin-triggered lipoxin promotes the resolution of inflammation and acts as antioxidant and immunomodulator. It also blocks the generation of reactive oxygen species in endothelial cells; it is a potent anti-inflammatory factor, inhibiting leukocyte-endothelial interaction and cell chemiotaxis of neutrophils while promoting monocyte chemiotaxis and non-phlogistic phagocytosis of apoptotic neutrophils by macrophages; it inhibits NF- $\kappa \mathrm{B}$ activation, and TNF- $\alpha$ secretion in activated $\mathrm{T}$ cells (67-69). The effect of ATL has been used successfully in a wide range of murine disease models such as experimental asthma, trimellitic anhydride-induced delayed type of hypersensitivity reaction, chronic airway inflammation, and infection associated with cystic fibrosis. Additionally, ATL inhibits proliferation and angiogenesis in proliferative states such as chronic inflammation, ischemic diseases, and cancer $(67,70-72)$. These results open a range of potential therapeutic uses of ATL in a variety of inflammatory diseases.

Some authors have shown that the anti-inflammatory activity of aspirin is due to the production of nitric oxide (NO) and that this effect is mediated by the ATL-induced NO synthesis through constitutive and inducible NO synthases (eNOS and iNOS, 
respectively) $(25,73)$. Meanwhile other authors argue that in the aspirin-mediated NO production the heme oxygenase-1 protein (HO-1) is involved, suggesting that more than one signaling pathway may be implicated. HO-1 is the inducible enzyme that catabolizes heme, leading to the generation of bilirubin, carbon monoxide, and iron. These molecules have antioxidant, antiapoptotic, and cytoprotective properties $(74,75)$.

Although the usefulness of the ATL in the field of reproduction has not been studied extensively, some reports suggest the possibilities for its use in this context. An increase of ALXR expression in the human endometrium during the menstrual cycle and in decidua during the first trimester of pregnancy was observed (76). In our group, we evaluated the effect of ATL on the inflammatory and oxidative response induced by plasma from preeclamptic women on endothelial cells (human umbilical venous endothelial cells). First, increased amounts of antiangiogenic factors (sFlt-1), pro-inflammatory (TNF) mediators, and products of lipid peroxidation (TBARS and 8-isoprostane) in preeclamptic plasma were observed. Besides, leukocyte adhesion to endothelial cells was evaluated and both preeclamptic plasma and exogenous TBARS, and 8-isoprostane increased neutrophil adhesion to these cells, and this inflammatory response was reduced when neutrophils were incubated with ATL prior to coculture with endothelial cells (77). On the other hand, we assessed the modulatory effects of ATL over some aPL-altered trophoblast functions: the monoclonal anti- $\beta_{2}$ GPI antibodies ID2 and IIC5 significantly reduced spontaneous trophoblast cell migration and also disrupted the trophoblast-endothelial cell interactions evaluated by a three-dimensional in vitro system of vascular remodeling. Both, migration and stability of the cocultures, were restored with simultaneous incubation with ATL. Similar results were obtained with serum samples from aPL-positive patients either with pregnancy morbidity alone (PM serum) or pregnancy morbidity plus vascular thrombosis (PM/VT) but ATL only restored aPL-altered trophoblast functions in the PM group, which could be an indication that the additional use of heparin is required in patients with PM/VT. An anti-inflammatory effect of ATL could not be demonstrated in these assays since ATL treatment did not resolve the aPL-induced pro-inflammatory and antiangiogenic responses of trophoblasts evaluated in terms of trophoblast secretion of the pro-inflammatory chemokine IL-8, the proangiogenic factor placental growth factor (PLGF) or the antiangiogenic factor soluble endoglin (59). As a whole, these findings the possibility of using ATL as an adjuvant therapy for women with PE or obstetric APS.

\section{ASPIRIN-INDUCED LIPID MEDIATORS DERIVED FROM OMEGA-3 PUFAs: DO THEY HAVE SOME POTENTIAL USE IN PREGNANCY COMPLICATIONS?}

Other lipid mediators derived from omega-3 PUFAs, eicosapentaenoic acid (EPA) and docosahexaenoic acid (DHA), have been described more recently. EPA-derived mediators include resolvin E1 (RvE1) and RvE2; the DHA-derived mediators described are $\mathrm{D}$-series resolvins, protectin $\mathrm{D} 1$, and maresins. Aspirin can induce the formation of RvE1 and the AT D-series resolvins, in a similar way to those of ATL (9). These mediators have potent pro-resolving inflammation activities (8). There are very few reports of the effect of endogenous lipid mediators or AT mediators derived from omega-3 PUFAs in pregnancy (78), but it has been reported that the dietary intake of these fatty acids increases resolvin and protectin levels in the rat placenta (79), and it has been proposed that omega-3 supplementation prevents preterm birth in humans (80).

Theoretically, the combination of omega-3 and LDA could have a synergistic effect in controlling inflammation. Some studies have found this effect in different scenarios: in TLR-7-activated microglia cells (81), in the treatment of three patients with progressive IgA nephropathy (82), and in the decrease of atherosclerosis in apoE-null mice (83). On the other hand, other authors, in a group of healthy volunteers, did not find any effect of aspirin on the production of pro-resolving lipid mediators (84), nor that the presence of aspirin had any additional effect to that of the omega- 3 PUFA in decreasing markers of inflammation (85). The beneficial effect it could have by the combination of omega-3 PUFAs and LDA in preventing pregnancy complications such as PE, based on the production of AT-resolvins requires further studies.

\section{CONCLUDING REMARKS}

Aspirin, and particularly LDA, has a therapeutical potential beyond its already known effects in the prevention of several diseases such as myocardial infarction, strokes, atherothrombotic events, $\mathrm{PE}$, and colon cancer. Besides the pharmacological effects that it shares with other NSAIDs, aspirin can induce other lipid-derived mediators with potent anti-inflammatory actions, and stimulation of the resolution of inflammation places aspirin in a privileged position in the therapeutic arsenal. In the context of prevention of some alterations of pregnancy, the prescription of drugs must be particularly careful to minimize the risk in both mother and fetus and even though aspirin is not exempt of risks, the risk-benefit balance is directed in favor of the beneficial effects. The use of LDA to prevent pregnancy complications such as PE and obstetric APS has been based on the restauration of the prostacyclin/ thromboxane-A2 balance to the dominance of the former. This action is due to aspirin's property to inhibit COX: platelets do not synthetize new protein, but endothelial cells do. However, in the light of newly identified mechanisms of action of aspirin, other immunomodulatory, anti-inflammatory, and antioxidant effects might be explored. The proposed challenge is a deep study of the molecular mechanisms implied in the effects of aspirin and of AT mediators to propose a more rational use of it based on the selection of patients who could benefit from aspirin, when the treatment should begin, and the dose that should be used.

\section{AUTHOR CONTRIBUTIONS}

APC wrote the manuscript and approved it for publication.

\section{FUNDING}

This work was financially supported by Colciencias-Colombia (Grant \# 111571249846) and CODI-University of Antioquia (Grant \# 91515). The author acknowledges Dr. Anne-Lise Haenni for her critical review. 


\section{REFERENCES}

1. Duley L, Henderson-Smart DJ, Meher S, King JF. Antiplatelet agents for preventing pre-eclampsia and its complications. Cochrane Database Syst Rev (2007) 2:CD004659. doi:10.1002/14651858.CD004659.pub2

2. Bartsch E, Park AL, Kingdom JC, Ray JG. Risk threshold for starting low dose aspirin in pregnancy to prevent preeclampsia: an opportunity at a low cost. PLoS One (2015) 10(3):e0116296. doi:10.1371/journal.pone.0116296

3. Roberge S, Nicolaides K, Demers S, Hyett J, Chaillet N, Bujold E. The role of aspirin dose on the prevention of preeclampsia and fetal growth restriction: systematic review and meta-analysis. Am J Obstet Gynecol (2017) 216(2):11020.e6. doi:10.1016/j.ajog.2016.09.076

4. Pattison NS, Chamley LW, Birdsall M, Zanderigo AM, Liddell HS, McDougall J. Does aspirin have a role in improving pregnancy outcome for women with the antiphospholipid syndrome? A randomized controlled trial. Am J Obstet Gynecol (2000) 183(4):1008-12. doi:10.1067/mob.2000.106754

5. Branch DW, Khamashta MA. Antiphospholipid syndrome: obstetric diagnosis, management, and controversies. Obstet Gynecol (2003) 101(6):1333-44. doi:10.1097/00006250-200306000-00031

6. Cadavid A, Lopera J, Gil-Villa A. Potential use of aspirin triggered lipoxins in alterations of the gestation. Placenta. Abstracts for the V Latin American Symposium on Maternal-Fetal Interaction and Placenta and IV Latin American Symposium on Reproductive Immunology Meeting 2013. (Vol. 34), Foz de Iguazu, Brazil (2013). A90 p.

7. Cadavid JAP. Aspirin: the mechanism of action revisited in the context of pregnancy complications. Front Immunol (2015) 5:89; Conference Abstract: IMMUNOCOLOMBIA2015 - 11th Congress of the Latin American Association of Immunology - 10o. Congreso de la Asociación Colombiana de Alergia, Asma e Inmunología. doi:10.3389/conf.fimmu.2015.05.00089

8. Serhan CN. Controlling the resolution of acute inflammation: a new genus of dual anti-inflammatory and proresolving mediators. J Periodontol (2008) 79(8 Suppl):1520-6. doi:10.1902/jop.2008.080231

9. Serhan CN, Clish CB, Brannon J, Colgan SP, Chiang N, Gronert K. Novel functional sets of lipid-derived mediators with antiinflammatory actions generated from omega-3 fatty acids via cyclooxygenase 2-nonsteroidal antiinflammatory drugs and transcellular processing. JExp Med (2000) 192(8):1197-204. doi:10.1084/jem.192.8.1197

10. Nicolaou KC, Montagnon T. Molecules that Changed the World. Weinheim: Wiley-VCH (2008).

11. Schrör K. Acetylsalicylic Acid. Weinheim: John Wiley and Sons (2010).

12. Vane JR. Inhibition of prostaglandin synthesis as a mechanism of action for aspirin-like drugs. Nat New Biol (1971) 231(25):232-5. doi:10.1038/ newbio231232a0

13. Smith JB, Willis AL. Aspirin selectively inhibits prostaglandin production in human platelets. Nat New Biol (1971) 231(25):235-7. doi:10.1038/ newbio231235a0

14. Kune GA, Kune S, Watson LF. Colorectal cancer risk, chronic illnesses, operations, and medications: case control results from the Melbourne Colorectal Cancer Study. Cancer Res (1988) 48(15):4399-404. doi:10.1093/ije/dym193

15. Acheson J, Archibald D, Barnett H, Blakely J, Bousser M-G, Boysen G, et al. Secondary prevention of vascular disease by prolonged antiplatelet treatment. Antiplatelet Trialists' Collaboration. Br Med J (Clin Res Ed) (1988) 296(6618):320-31.

16. Hunt D, Varigos J, Carlisle C, Falconer P, Landy T, Smedley A, et al. Randomized trial of intravenous streptokinase, oral aspirin, both, or neither among 17,187 cases of suspected acute myocardial infarction: ISIS-2. ISIS-2 (Second International Study of Infarct Survival) Collaborative Group. J Am Coll Cardiol (1988) 12(6 Suppl A):3A-13A.

17. Crandon AJ, Isherwood DM. Effect of aspirin on incidence of pre-eclampsia. Lancet (1979) 1(8130):1356. doi:10.1016/S0140-6736(79)91996-2

18. Claria J, Serhan CN. Aspirin triggers previously undescribed bioactive eicosanoids by human endothelial cell-leukocyte interactions. Proc Natl Acad Sci U S A (1995) 92(21):9475-9. doi:10.1073/pnas.92.21.9475

19. Saunders MA, Sansores-Garcia L, Gilroy DW, Wu KK. Selective suppression of CCAAT/enhancer-binding protein beta binding and cyclooxygenase-2 promoter activity by sodium salicylate in quiescent human fibroblasts. J Biol Chem (2001) 276(22):18897-904. doi:10.1074/jbc.M011147200
20. Pereira-Leite C, Nunes C, Reis S. Interaction of nonsteroidal anti-inflammatory drugs with membranes: in vitro assessment and relevance for their biological actions. Prog Lipid Res (2013) 52(4):571-84. doi:10.1016/j.plipres.2013.08.003

21. Urra FA, Cordova-Delgado M, Lapier M, Orellana-Manzano A, AcevedoArevalo L, Pessoa-Mahana H, et al. Small structural changes on a hydroquinone scaffold determine the complex I inhibition or uncoupling of tumoral oxidative phosphorylation. Toxicol Appl Pharmacol (2016) 291:46-57. doi:10.1016/j.taap.2015.12.005

22. Yin MJ, Yamamoto Y, Gaynor RB. The anti-inflammatory agents aspirin and salicylate inhibit the activity of I(kappa)B kinase-beta. Nature (1998) 396(6706):77-80. doi:10.1038/23948

23. Shi X, Ding M, Dong Z, Chen F, Ye J, Wang S, et al. Antioxidant properties of aspirin: characterization of the ability of aspirin to inhibit silica-induced lipid peroxidation, DNA damage, NF-kappaB activation, and TNF-alpha production. Mol Cell Biochem (1999) 199(1-2):93-102.

24. Roth GJ, Stanford N, Majerus PW. Acetylation of prostaglandin synthase by aspirin. Proc Natl Acad Sci U S A (1975) 72(8):3073-6. doi:10.1073/ pnas.72.8.3073

25. Taubert D, Berkels R, Grosser N, Schroder H, Grundemann D, Schomig E. Aspirin induces nitric oxide release from vascular endothelium: a novel mechanism of action. Br J Pharmacol (2004) 143(1):159-65. doi:10.1038/ sj.bjp. 0705907

26. Grosser N, Abate A, Oberle S, Vreman HJ, Dennery PA, Becker JC, et al. Heme oxygenase-1 induction may explain the antioxidant profile of aspirin. Biochem Biophys Res Commun (2003) 308(4):956-60. doi:10.1016/ S0006-291X(03)01504-3

27. Schroder H. New signaling routes for an old drug: lipoxin A4 might mediate heme oxygenase-1 induction by aspirin. Focus on "Novel lipid mediator aspirin-triggered lipoxin A4 induces heme oxygenase-1 in endothelial cells". Am J Physiol Cell Physiol (2005) 289(3):C507-8. doi:10.1152/ajpcell.00230.2005

28. Pinckard RN, Hawkins D, Farr RS. In vitro acetylation of plasma proteins, enzymes and DNA by aspirin. Nature (1968) 219(5149):68-9. doi:10.1038/219068a0

29. Alfonso LF, Srivenugopal KS, Bhat GJ. Does aspirin acetylate multiple cellular proteins? (Review). Mol Med Rep (2009) 2(4):533-7. doi:10.3892/ mmr_00000132

30. Tohgi H, Konno S, Tamura K, Kimura B, Kawano K. Effects of low-to-high doses of aspirin on platelet aggregability and metabolites of thromboxane A2 and prostacyclin. Stroke (1992) 23(10):1400-3. doi:10.1161/01.STR.23.10.1400

31. American College of Obstetricians and Gynecologists. Task force on hypertension in P. hypertension in pregnancy. Report of the American College of Obstetricians and Gynecologists' task force on hypertension in pregnancy. Obstet Gynecol (2013) 122(5):1122-31. doi:10.1097/01. AOG.0000437382.03963.88

32. Redman CW, Sargent IL. Latest advances in understanding preeclampsia. Science (2005) 308(5728):1592-4. doi:10.1126/science.1111726

33. Redman C. Pre-eclampsia and the placenta. Placenta (1991) 12(4):301-8. doi:10.1016/0143-4004(91)90339-H

34. Sanchez-Aranguren LC, Prada CE, Riano-Medina CE, Lopez M. Endothelial dysfunction and preeclampsia: role of oxidative stress. Front Physiol (2014) 5:372. doi:10.3389/fphys.2014.00372

35. Sibai BM, Caritis SN, Thom E, Klebanoff M, McNellis D, Rocco L, et al. Prevention of preeclampsia with low-dose aspirin in healthy, nulliparous pregnant women. N Engl J Med (1993) 329(17):1213-8.

36. Beroyz G, Casale R, Farreiros A, Palermo M, Margulies M, Voto L, et al. Randomised trial of intravenous streptokinase, oral aspirin, both, or neither among 17,187 cases of suspected acute myocardial infarction: ISIS-2. ISIS-2 (Second International Study of Infarct Survival) Collaborative Group. Lancet (1988) 2(8607):349-60. doi:10.1016/S0140-6736(88)92833-4

37. Villa PM, Kajantie E, Raikkonen K, Pesonen AK, Hamalainen E, Vainio M, et al. Aspirin in the prevention of pre-eclampsia in high-risk women: a randomised placebo-controlled PREDO Trial and a meta-analysis of randomised trials. BJOG (2013) 120(1):64-74. doi:10.1111/j.1471-0528.2012.03493.x

38. Meher S, Duley L, Hunter K, Askie L. Antiplatelet therapy before or after 16 weeks' gestation for preventing preeclampsia: an individual participant data meta-analysis. Am J Obstet Gynecol (2017) 216(2):121-8.e2. doi:10.1016/j. ajog.2016.10.016 
39. Norgard B, Puho E, Czeizel AE, Skriver MV, Sorensen HT. Aspirin use during early pregnancy and the risk of congenital abnormalities: a population-based case-control study. Am J Obstet Gynecol (2005) 192(3):922-3. doi:10.1016/j. ajog.2004.10.598

40. Bujold E, Roberge S, Lacasse Y, Bureau M, Audibert F, Marcoux S, et al. Prevention of preeclampsia and intrauterine growth restriction with aspirin started in early pregnancy: a meta-analysis. Obstet Gynecol (2010) 116(2 Pt 1):402-14. doi:10.1097/AOG.0b013e3181e9322a

41. Schisterman EF, Silver RM, Lesher LL, Faraggi D, Wactawski-Wende J, Townsend JM, et al. Preconception low-dose aspirin and pregnancy outcomes: results from the EAGeR randomised trial. Lancet (2014) 384(9937):29-36. doi:10.1016/S0140-6736(14)60157-4

42. Mone F, Mulcahy C, McParland P, McAuliffe FM. Should we recommend universal aspirin for all pregnant women? Am J Obstet Gynecol (2017) 216(2):141. e1-e5. doi:10.1016/j.ajog.2016.09.086

43. Miyakis S, Lockshin MD, Atsumi T, Branch DW, Brey RL, Cervera R, et al. International consensus statement on an update of the classification criteria for definite antiphospholipid syndrome (APS). J Thromb Haemost (2006) 4(2):295-306. doi:10.1111/j.1538-7836.2006.01753.x

44. La Rosa L, Meroni PL, Tincani A, Balestrieri G, Faden D, Lojacono A, et al. Beta 2 glycoprotein I and placental anticoagulant protein I in placentae from patients with antiphospholipid syndrome. J Rheumatol (1994) 21(9):1684-93.

45. Girardi G, Berman J, Redecha P, Spruce L, Thurman JM, Kraus D, et al. Complement $\mathrm{C} 5$ a receptors and neutrophils mediate fetal injury in the antiphospholipid syndrome. J Clin Invest (2003) 112(11):1644-54. doi:10.1172/ JCI18817

46. Girardi G, Salmon JB. The role of complement in pregnancy and fetal loss. Autoimmunity (2003) 36(1):19-26. doi:10.1080/0891693031000067322

47. Di Simone N, Ferrazzani S, Castellani R, De Carolis S, Mancuso S, Caruso A. Heparin and low-dose aspirin restore placental human chorionic gonadotrophin secretion abolished by antiphospholipid antibody-containing sera. Hum Reprod (1997) 12(9):2061-5. doi:10.1093/humrep/12.9.2061

48. Meroni PL, Borghi MO, Raschi E, Tedesco F. Pathogenesis of antiphospholipid syndrome: understanding the antibodies. Nat Rev Rheumatol (2011) 7(6):330-9. doi:10.1038/nrrheum.2011.52

49. Mulla MJ, Brosens JJ, Chamley LW, Giles I, Pericleous C, Rahman A, et al. Antiphospholipid antibodies induce a pro-inflammatory response in first trimester trophoblast via the TLR4/MyD88 pathway. Am J Reprod Immunol (2009) 62(2):96-111. doi:10.1111/j.1600-0897.2009.00717.x

50. Di Simone N, Caliandro D, Castellani R, Ferrazzani S, De Carolis S, Caruso A. Low-molecular weight heparin restores in-vitro trophoblast invasiveness and differentiation in presence of immunoglobulin $\mathrm{G}$ fractions obtained from patients with antiphospholipid syndrome. Hum Reprod (1999) 14(2):489-95. doi:10.1093/humrep/14.2.489

51. Mulla MJ, Myrtolli K, Brosens JJ, Chamley LW, Kwak-Kim JY, Paidas MJ, et al. Antiphospholipid antibodies limit trophoblast migration by reducing IL-6 production and STAT3 activity. Am J Reprod Immunol (2010) 63(5):339-48. doi:10.1111/j.1600-0897.2009.00805.x

52. Chamley LW, Duncalf AM, Mitchell MD, Johnson PM. Action of anticardiolipin and antibodies to beta2-glycoprotein-I on trophoblast proliferation as a mechanism for fetal death. Lancet (1998) 352(9133):1037-8. doi:10.1016/ S0140-6736(05)60080-3

53. Jovanovic M, Bozic M, Kovacevic T, Radojcic L, Petronijevic M, Vicovac L. Effects of anti-phospholipid antibodies on a human trophoblast cell line (HTR-8/SVneo). Acta Histochem (2010) 112(1):34-41. doi:10.1016/j. acthis.2008.07.001

54. Adler RR, Ng AK, Rote NS. Monoclonal antiphosphatidylserine antibody inhibits intercellular fusion of the choriocarcinoma line, JAR. Biol Reprod (1995) 53(4):905-10. doi:10.1095/biolreprod53.4.905

55. Bose P, Kadyrov M, Goldin R, Hahn S, Backos M, Regan L, et al. Aberrations of early trophoblast differentiation predispose to pregnancy failure: lessons from the anti-phospholipid syndrome. Placenta (2006) 27(8):869-75. doi:10.1016/j. placenta.2005.09.007

56. Katsuragawa H, Kanzaki H, Inoue T, Hirano T, Mori T, Rote NS. Monoclonal antibody against phosphatidylserine inhibits in vitro human trophoblastic hormone production and invasion. Biol Reprod (1997) 56(1):50-8. doi:10.1095/biolreprod56.1.50

57. Di Simone N, Luigi MP, Marco D, Fiorella DN, Silvia D, Clara DM, et al. Pregnancies complicated with antiphospholipid syndrome: the pathogenic mechanism of antiphospholipid antibodies: a review of the literature. Ann N Y Acad Sci (2007) 1108:505-14. doi:10.1196/annals.1422.054

58. Mineo C, Shaul PW. New insights into the molecular basis of the antiphospholipid syndrome. Drug Discov Today Dis Mech (2011) 8(1-2):e47-52. doi:10.1016/j.ddmec.2011.12.002

59. Alvarez AM, Mulla MJ, Chamley LW, Cadavid AP, Abrahams VM. Aspirintriggered lipoxin prevents antiphospholipid antibody effects on human trophoblast migration and endothelial cell interactions. Arthritis Rheumatol (2015) 67(2):488-97. doi:10.1002/art.38934

60. Laskin CA, Spitzer KA, Clark CA, Crowther MR, Ginsberg JS, Hawker GA, et al. Low molecular weight heparin and aspirin for recurrent pregnancy loss: results from the randomized, controlled HepASA Trial. J Rheumatol (2009) 36(2):279-87. doi:10.3899/jrheum.080763

61. Empson M, Lassere M, Craig J, Scott J. Prevention of recurrent miscarriage for women with antiphospholipid antibody or lupus anticoagulant. Cochrane Database Syst Rev (2005) 2:CD002859. doi:10.1002/14651858.CD002859. pub2

62. Andrade D, Tektonidou M. Emerging therapies in antiphospholipid syndrome. Curr Rheumatol Rep (2016) 18(4):22. doi:10.1007/s11926-016-0566-Z

63. Ruffatti A, Hoxha A, Favaro M, Tonello M, Colpo A, Cucchini U, et al. Additional treatments for high-risk obstetric antiphospholipid syndrome: a comprehensive review. Clin Rev Allergy Immunol (2016). doi:10.1007/ s12016-016-8571-6

64. Krause I, Blank M, Gilbrut B, Shoenfeld Y. The effect of aspirin on recurrent fetal loss in experimental antiphospholipid syndrome. Am J Reprod Immunol (1993) 29(3):155-61. doi:10.1111/j.1600-0897.1993.tb00581.x

65. Cadavid A, Sanchez F, Botero J, Peña B, Castañeda A, Ossa JE. Coadjuvant effect of aspirin in the treatment of recurrent spontaneous abortion. Am J Reprod Immunol (1996) 35:465; Abstract for the 16th American Society Reproductive Immunology Meeting, June-26-29, 1996. Knoxville, USA.

66. Cadavid A, Pena B, Garcia G, Botero J, Sanchez F, Ossa J, et al. Heparin plus aspirin as a "single" therapy for recurrent spontaneous abortion associated with both allo- and autoimmunity. Am J Reprod Immunol (1999) 41(4):271-8. doi:10.1111/j.1600-0897.1999.tb00438.x

67. Parkinson JF. Lipoxin and synthetic lipoxin analogs: an overview of anti-inflammatory functions and new concepts in immunomodulation. Inflamm Allergy Drug Targets (2006) 5(2):91-106. doi:10.2174/187152806776 383125

68. Godson C, Mitchell S, Harvey K, Petasis NA, Hogg N, Brady HR. Cutting edge: lipoxins rapidly stimulate nonphlogistic phagocytosis of apoptotic neutrophils by monocyte-derived macrophages. J Immunol (2000) 164(4):1663-7. doi:10.4049/jimmunol.164.4.1663

69. Nascimento-Silva V, Arruda MA, Barja-Fidalgo C, Fierro IM. Aspirintriggered lipoxin A4 blocks reactive oxygen species generation in endothelial cells: a novel antioxidative mechanism. Thromb Haemost (2007) 97(1):88-98. doi:10.1160/TH06-06-0315

70. Bandeira-Melo C, Bozza PT, Diaz BL, Cordeiro RS, Jose PJ, Martins MA, et al. Cutting edge: lipoxin (LX) A4 and aspirin-triggered 15-epi-LXA4 block allergen-induced eosinophil trafficking. J Immunol (2000) 164(5):2267-71. doi:10.4049/jimmunol.164.5.2267

71. Chiang N, Serhan CN, Dahlen SE, Drazen JM, Hay DW, Rovati GE, et al. The lipoxin receptor ALX: potent ligand-specific and stereoselective actions in vivo. Pharmacol Rev (2006) 58(3):463-87. doi:10.1124/pr.58.3.4

72. Levy BD, Lukacs NW, Berlin AA, Schmidt B, Guilford WJ, Serhan CN, et al. Lipoxin A4 stable analogs reduce allergic airway responses via mechanisms distinct from CysLT1 receptor antagonism. FASEB J (2007) 21(14):3877-84. doi:10.1096/fj.07-8653com

73. Gilroy DW. The role of aspirin-triggered lipoxins in the mechanism of action of aspirin. Prostaglandins Leukot Essent Fatty Acids (2005) 73(3-4):203-10. doi:10.1016/j.plefa.2005.05.007

74. Nascimento-Silva V, Arruda MA, Barja-Fidalgo C, Villela CG, Fierro IM. Novel lipid mediator aspirin-triggered lipoxin A4 induces heme oxygenase-1 in endothelial cells. Am J Physiol Cell Physiol (2005) 289(3):C557-63. doi:10.1152/ajpcell.00045.2005

75. Schroder H. Nitric oxide and aspirin: a new mediator for an old drug. Am J Ther (2009) 16(1):17-23. doi:10.1097/MJT.0b013e318164bd60

76. Macdonald LJ, Boddy SC, Denison FC, Sales KJ, Jabbour HN. A role for lipoxin A(4) as an anti-inflammatory mediator in the human endometrium. Reproduction (2011) 142(2):345-52. doi:10.1530/REP-11-0021 
77. Gil-Villa AM, Norling LV, Serhan CN, Cordero D, Rojas M, Cadavid A. Aspirin triggered-lipoxin A4 reduces the adhesion of human polymorphonuclear neutrophils to endothelial cells initiated by preeclamptic plasma. Prostaglandins Leukot Essent Fatty Acids (2012) 87(4-5):127-34. doi:10.1016/j. plefa.2012.08.003

78. Greenberg JA, Bell SJ, Ausdal WV. Omega-3 fatty acid supplementation during pregnancy. Rev Obstet Gynecol (2008) 1(4):162-9.

79. Keelan JA, Mas E, D’Vaz N, Dunstan JA, Li S, Barden AE, et al. Effects of maternal n-3 fatty acid supplementation on placental cytokines, pro-resolving lipid mediators and their precursors. Reproduction (2015) 149(2):171-8. doi:10.1530/REP-14-0549

80. Coletta JM, Bell SJ, Roman AS. Omega-3 Fatty acids and pregnancy. Rev Obstet Gynecol (2010) 3(4):163-71.

81. Pettit LK, Varsanyi C, Tadros J, Vassiliou E. Modulating the inflammatory properties of activated microglia with docosahexaenoic acid and aspirin. Lipids Health Dis (2013) 12:16. doi:10.1186/1476-511X-12-16

82. Hirahashi J, Hanafusa N, Wada T, Arita M, Hishikawa K, Hayashi M, et al. Aspirin and eicosapentaenoic acid may arrest progressive IgA nephropathy: a potential alternative to immunosuppression. Intern Med (2015) 54(18):237782. doi:10.2169/internalmedicine.54.4623

83. Sorokin AV, Yang ZH, Vaisman BL, Thacker S, Yu ZX, Sampson M, et al. Addition of aspirin to a fish oil-rich diet decreases inflammation and atherosclerosisin ApoE-nullmice.J NutrBiochem (2016)35:58-65.doi:10.1016/ j.jnutbio.2016.05.012

84. Barden A, Mas E, Croft KD, Phillips M, Mori TA. Short-term n-3 fatty acid supplementation but not aspirin increases plasma proresolving mediators of inflammation. J Lipid Res (2014) 55(11):2401-7. doi:10.1194/ jlr.M045583

85. Block RC, Dier U, Calderonartero P, Shearer GC, Kakinami L, Larson MK, et al. The effects of EPA+DHA and aspirin on inflammatory cytokines and angiogenesis factors. World J Cardiovasc Dis (2012) 2(1):14-9. doi:10.4236/ wjcd.2012.21003

Conflict of Interest Statement: The author declares that the research was conducted in the absence of any commercial or financial relationships that could be construed as a potential conflict of interest.

Copyright (c) 2017 Cadavid. This is an open-access article distributed under the terms of the Creative Commons Attribution License (CC BY). The use, distribution or reproduction in other forums is permitted, provided the original author(s) or licensor are credited and that the original publication in this journal is cited, in accordance with accepted academic practice. No use, distribution or reproduction is permitted which does not comply with these terms. 